\title{
One-year survival rate of renal transplant: factors influencing the outcome
}

This article was published in the following Dove Press journal: Transplant Research and Risk Management

\author{
Siavash Rezapour' \\ Aliasghar Yarmohammadi ${ }^{1,2}$ \\ Mahmoud Tavakkoli ${ }^{1,2}$ \\ 'Mashhad University of Medical \\ Sciences, ${ }^{2}$ Urology Department, \\ Montaserie Organ Transplantation \\ Hospital, Mashhad University of \\ Medical Sciences, Mashhad, Iran
}

Correspondence: Siavash Rezapour 302/6 Yara Ave, Rozelle, NSW 2039, Australia

Tel +6I 040840 II38

Email Siavash_rezapour@yahoo.com
Background: Renal transplantation remains the treatment of choice for end-stage renal disease, as the procedure not only improves quality of life, but also markedly increases patients' survival rates. Organ and patient survival rates are important issues of interest post-transplantation.

Aim: To determine the 1-year survival rate of renal transplant, we studied graft function, which is a predictor of survival, among those who received a kidney transplant in the time period between February 2012 and February 2013 at Montaserie Organ Transplantation Hospital.

Materials and methods: This is a retrospective cohort study planned to determine patient and organ survival rates after kidney transplantation from living and deceased donors during a 1 -year period. We also tried to clarify factors resulting in graft loss. Designated variables were collected using checklists and subsequently entered into SPSS software version 17 and analyzed using the Kaplan-Meier method and descriptive statistics.

Results: From 173 patients included in the study, 67.1\% $(n=116)$ were female. The mean age of the recipients was $33 \pm 12.85$ years. In the majority of cases, cause of end-stage renal disease was not clear $(n=89,51.44 \%)$. Urinary tract infection $(23.1 \%)$ was the commonest post-operative complication, followed by delayed graft function, which was diagnosed in $22(12.7 \%)$ recipients. Seventeen cases of graft rejection (9.8\%) were recorded and 4 (2.3\%) of these cases underwent nephrectomy that will be regarded as graft loss in this paper. Therefore, 1-year graft survival was $90.2 \%$. Graft survival in cadaveric and live-donor recipients was $90.8 \%$ and $88.7 \%$, respectively. As there was no mortality reported among graft recipients, 1 -year patient survival rate was $100 \%$. It was found that graft rejection was marginally, but not significantly, higher with female donors. $(p=0.05)$.

Conclusion: One-year graft survival in our cohort was comparable with reports from the large centers in the world. Female donor can be a possible negative factor for graft outcome.

Keywords: renal transplantation, patient survival rate, graft survival rate, cadaveric donor, living donor

\section{Introduction}

Renal transplant is the treatment of choice for end-stage renal disease (ESRD). Following a successful renal transplantation, recipients regain renal function, which typically reaches as high as $\sim 60 \%$ of donor's previous function after graft stabilization. ${ }^{1}$ Thereafter, a gradual decline in renal function may typically occur. The decreased function rate may be influenced by numerous variables, including donor- and recipientrelated characteristics, delayed graft function (DGF) and acute rejection. ${ }^{2}$ We studied the patients' data who received a renal transplant in a time period of 1 year in a single transplant center in Iran. The main purpose of this study was to analyze the data, describe the rates of patient and graft survival and to find other risk factors, as predictors of patient and/or graft survival. 


\section{Materials and methods}

A retrospective cohort study was conducted at Montaserie Organ Transplantation Hospital, the first and the only organ transplant center in Eastern Iran, founded in 2012 by Professor Aliasghar Yarmohamadi. Clinical data was used to identify all renal transplant cases from both cadaveric and living donor between February 2012 and February 2013. We analyzed demographic and laboratory data at the time of admission and in 3 follow-up visits until 1 year after the transplantation. The main outcome measures were patient and graft survival, and patterns of graft function, as measured by creatinine levels.

Full data were available describing the history of care and outcome of almost all patients who had received at least 1 renal transplant at Montaserie Hospital, amounting to 173 subjects over the period of data collection.

The following data were collected: patient gender; age of donors and recipients at the time of transplantation; co-existence of relevant medical conditions; serial serum creatinine levels; episodes of DGF following transplantation; acute rejection episodes (AREs) and graft survival.

Patient survival was defined as the time between the final transplant and recorded death. Graft survival was defined as the time between any transplant and ESRD where ESRD was defined in the transplant unit as either the need to return to dialysis, need of a re-transplant or a serum creatinine level of $>5.6 \mathrm{mg} / \mathrm{dL}$. DGF is defined as the need for dialysis within the first 7 days post-transplantation. AREs were identified on either a histological basis; from a $10 \%$ increase in serum creatinine (with no other clinical explanation); or 3 or more consecutive prescriptions of methyl prednisolone for management.

Inclusion criteria were all the patients who had renal transplant at Montaserie Hospital in the targeted time frame. Patients were excluded from the study if the full data were missing. Deceased patients were included in the study if the transplanted kidney was functional at the time of death. Related variables collected through checklists were entered into SPSS software version 17 and analyzed using the Kaplan-Meier method and descriptive statistics.

This study has been approved by the research ethics committee of Mashhad University of Medical Sciences. In order to access hospital records, patients' consent was not required by the research ethics committee as these records can be used for research purposes up on authorization by the director of Montaserie Hospital, Professor Aliasghar Yarmohammadi, although patients' personal information will remain confidential.

\section{Results Demographics}

From February 2012 to February 2013, there were 173 renal transplant recipients in our center, out of which, 120 (69.4\%) underwent cadaveric graft and the rest had living donors $(\mathrm{n}=53,30.6 \%)$ (Figure 1).

One hundred and sixteen of recipients were female $(67.1 \%)$ and 57 were male (32.9\%). Also, there were 83 male donors (48\%) and 90 female donors (52\%) (Figure 2).

The median age of the recipients was $33 \pm 12.85$ years and for donors was $29.7 \pm 12.98$ years.

In the majority of cases, the condition leading to ESRD was not clear $(n=89,51.44 \%)$. Among those with a known underlying cause, the most common conditions were hypertension $(\mathrm{HTN})(\mathrm{n}=24,13.9 \%)$, diabetes mellitis (pre-existing) (DM) $(\mathrm{n}=16,9.2 \%)$, chronic pyelonephritis $(\mathrm{CPN})(\mathrm{n}=13,7.5 \%)$, urological anomalies $(\mathrm{n}=6,3.5 \%)$, vesicoureteral reflux $(n=6,3.5 \%)$, polycystic kidney disease $(n=5,2.9 \%)$, glomerulonephritis $(\mathrm{GN})(n=4,2.3 \%)$, nephrotic syndrome $(n=4,2.3 \%)$, Alport syndrome $(n=3$, $1.7 \%)$, neurogenic bladder $(\mathrm{n}=2,1.2 \%)$, and acute tubular necrosis $(n=1,0.6 \%)$, respectively (Figure 3$)$. As there was a big proportion of unknown causes for ESRD due to incomplete patient past medical records, it makes it impossible to draw any conclusions on this matter.

\section{Process measures}

The mean 24 hours urine output on the first, third, and seventh day post-transplant was $3829.7 \mathrm{~mL}, 2655.1 \mathrm{~mL}$, and 2978 $\mathrm{mL}$, respectively (Figure 4).

Serial serum creatinine levels were measured on day 1 , 3 , and 7 after transplant. Also, it was recorded at 1; 3 and 12 months post-transplantation follow-up visits. We observed that the levels gradually decreased over time (Figure 5).

\section{Post-transplant complications}

In our study, the most common complication after transplant was urinary tract infection (23.1\%), followed by hypovolemia leading to blood transfusion (13.3\%). DGF was the third most common (12.7\%) complication after the renal transplant. A total of $17.3 \%$ of our patients suffered from $>1$ post-operative complication (Figure 6).

\section{Graft rejection and graft survival rates}

Within 1 year, 17 cases of graft rejection $(9.8 \%)$ were recorded. Therefore, 1-year graft survival was $90.2 \%$ in our center. Graft survival in cadaveric and live-donor 


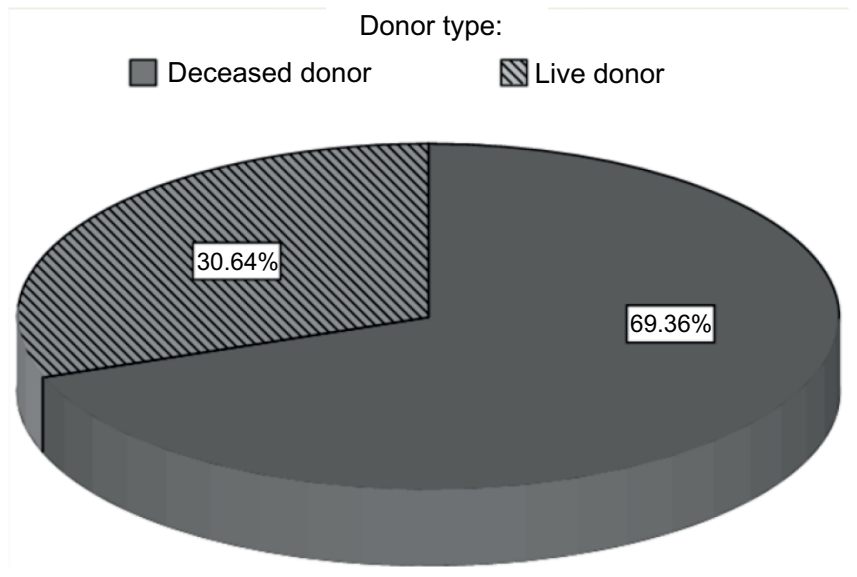

Figure I Donor source distribution.

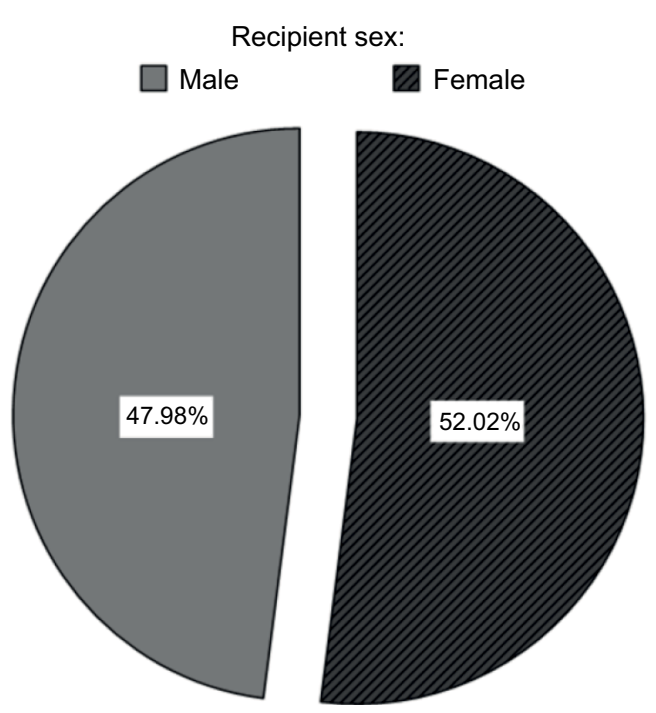

Figure 2 Gender distribution among donors and recipients.

recipients were $90.8 \%$ and $88.7 \%$, respectively. Despite showing higher graft survival rates from cadaver, the difference between 2 groups was not statistically significant (Figure 7).

\section{Association between graft survival/ rejection and demographic features}

The table below shows the association between demographic features and graft outcome in details. None of these factors reached statistical significance. However, female gender was borderline significant for graft rejection $(p=0.050)$ (Table 1).

In our study, we could not find any relationship between underlying cause of ESRD and graft survival rates, which may be due to not knowing the majority of patients' ESRD culprits. (Table 2).

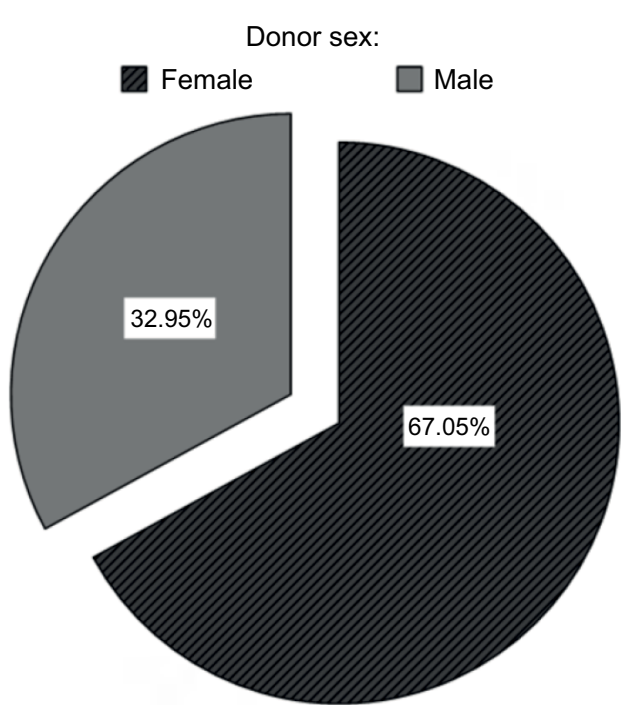

\section{Graft loss and mortality}

Within 1 year, 4 cases of graft loss (2.3\%), which was defined as a need for extraction of the transplanted kidney, were recorded. Based on these findings, 1-year patient survival rate was calculated as $100 \%$ (Table 3 ).

\section{Discussion}

ESRD is a serious illness with significant health consequences and high treatment costs. As seen worldwide, the prevalence of ESRD has significantly increased over the past decade. ${ }^{3,4}$ In the USA, the number of patients registered to ESRD program has increased from 10,000 in 1973 to 527,283 in 2008. ${ }^{4}$ In Iran, the incidence of ESRD has increased from 49.9 per million population (pmp) in 2000 to $63.8 \mathrm{pmp}$ in 2006. Although, the reason behind this is not clear, increase in 


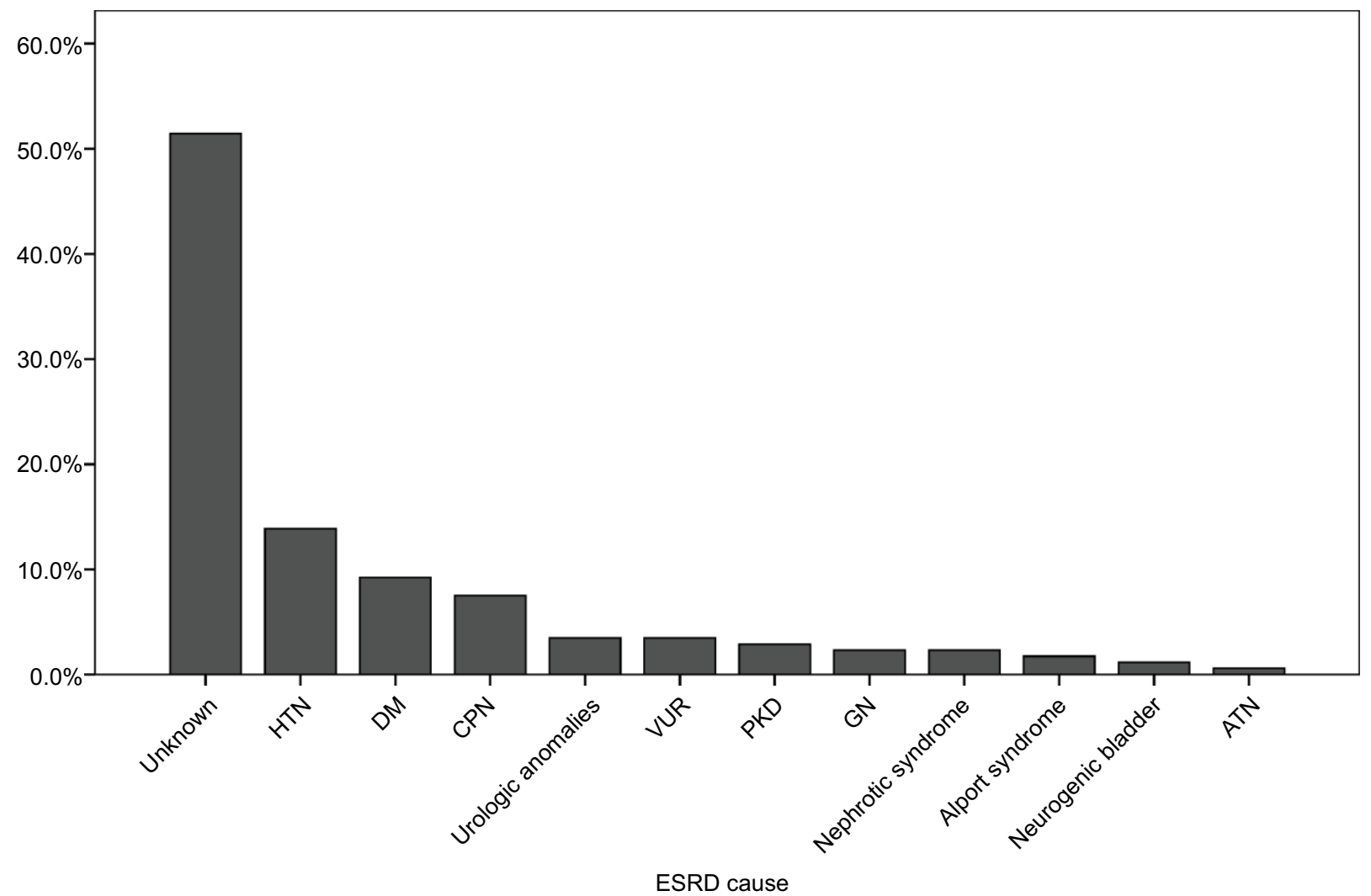

Figure 3 Underlying causes for ESRD in the study population.

Abbreviations: ATN, acute tubular necrosis; CPN, chronic pyelonephritis; DM, diabetes mellitis (pre-existing); ESRD, end-stage renal disease; GN, glomerulonephritis; HTN, hypertension; PKD, polycystic kidney disease; VUR, vesicoureteral reflux.

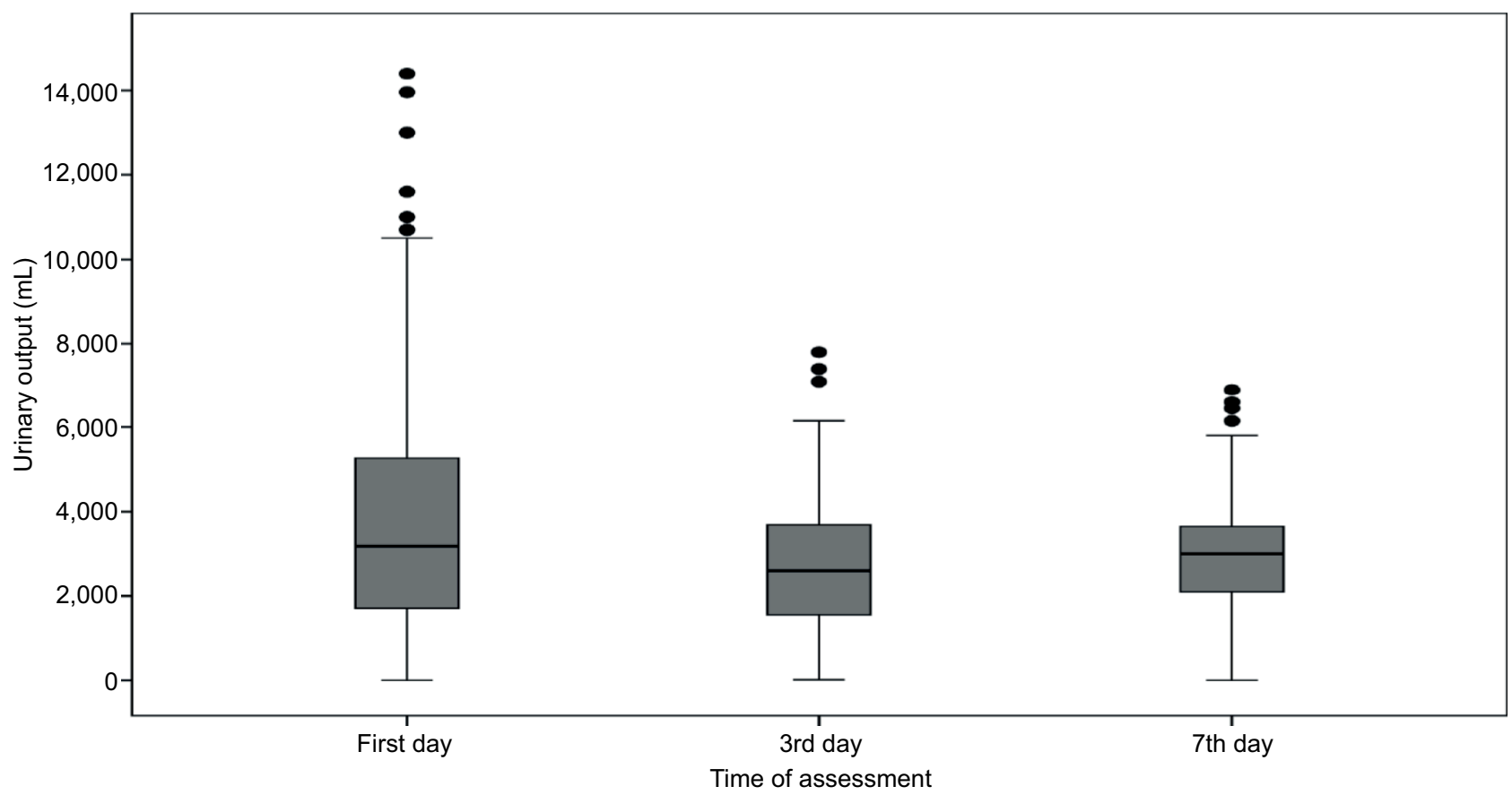

Figure 4 The 24-hour urine output 7 days after renal transplant. 


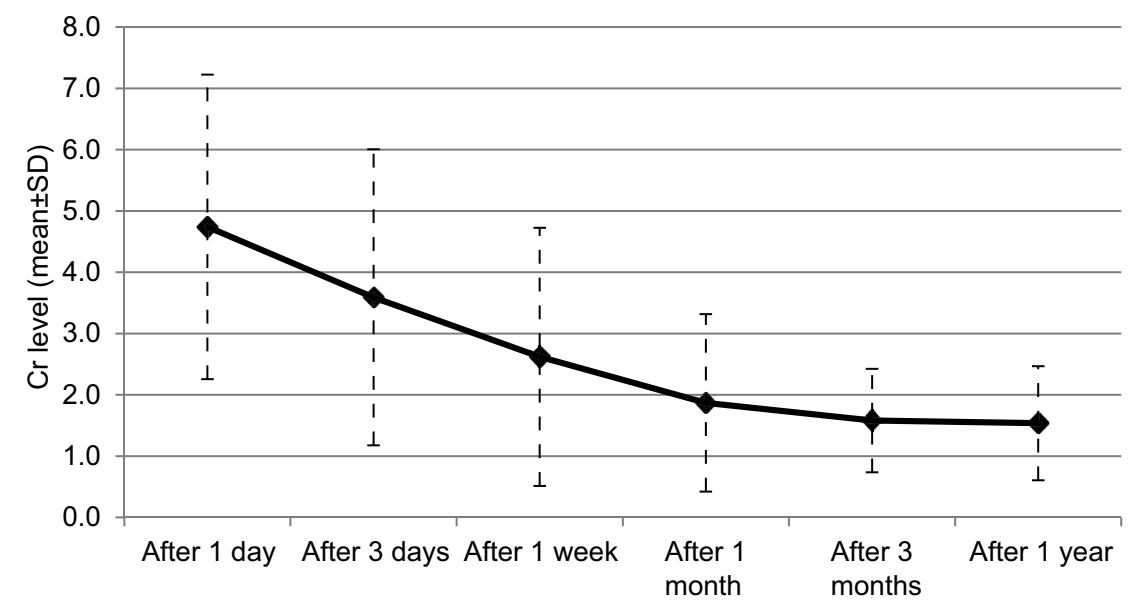

Time of assessment

Figure 5 Serial serum creatinine level after the renal transplant.

Abbreviation: $\mathrm{Cr}$, creatinine.

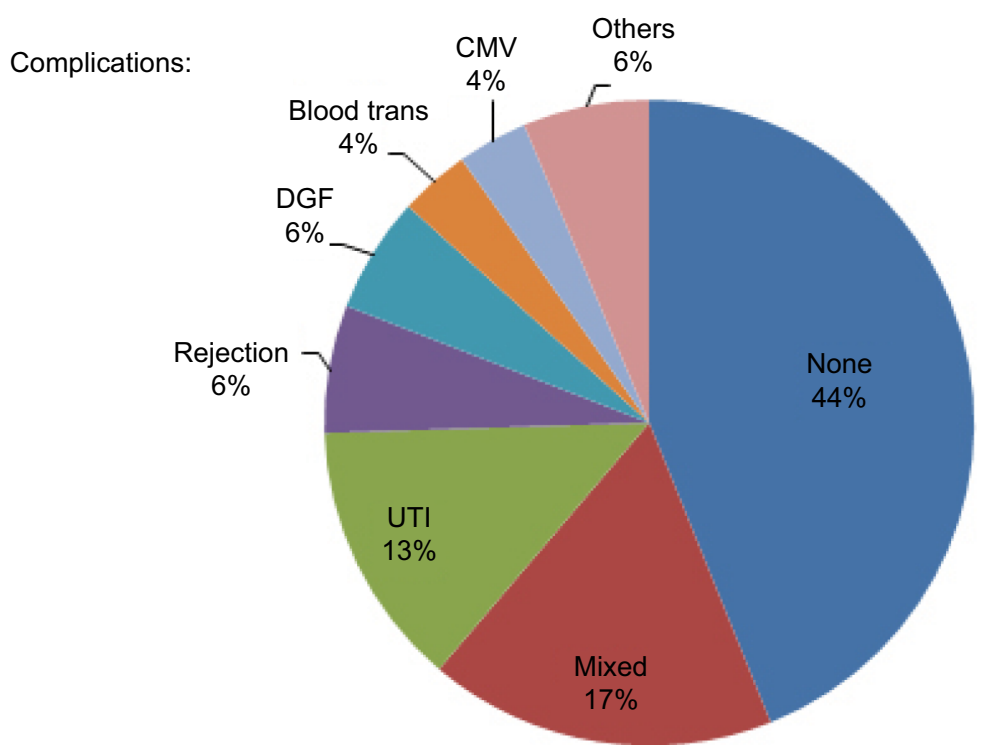

Figure 6 The prevalence of post graft complications.

Abbreviations: CMV, cytomegalovirus; DGF, delayed graft function; UTI, urinary tract infection.

prevalence of medical conditions such as obesity, DM, HTN, and cardiovascular disease may be the culprit. Another possible contributory factor is a longer life expectancy of ESRD patients compared with the past. ${ }^{5,6} \mathrm{GN}$ is the most commonly recognized cause of ESRD worldwide. ${ }^{7,8}$ In our study, the underlying cause of ESRD was unclear in the majority of the patients. HTN was the most common known condition leading to ESRD followed by DM and CPN.

Renal transplantation is the treatment of choice for patients with ESRD. A recent study estimated that projected life expectancy increased a further 3-17 years in those patients who underwent renal transplantation compared with patients who received hemodialysis. ${ }^{1}$ Although there are 3 different resources for organ attainment, including live related, live unrelated, and deceased donors, organ shortage is still the biggest obstacle restricting transplantation. ${ }^{9}$

In Iran, the rate of renal transplantation approximates 24 grafts per 1 million populations per year and almost half of ESRD patients are still on hemodialysis. ${ }^{3,9}$ Living unrelated donors are the largest (85\%) transplantation source. ${ }^{10}$ Cadaveric donation is lower than expected in Iran due to cultural, legal, and medical issues. ${ }^{11}$

Analysis of data from the United States Renal Data System suggests that projected graft survival has improved in the short term for both live donor and cadaveric donor transplant recipients. Patient survival for cadaveric transplant recipients 


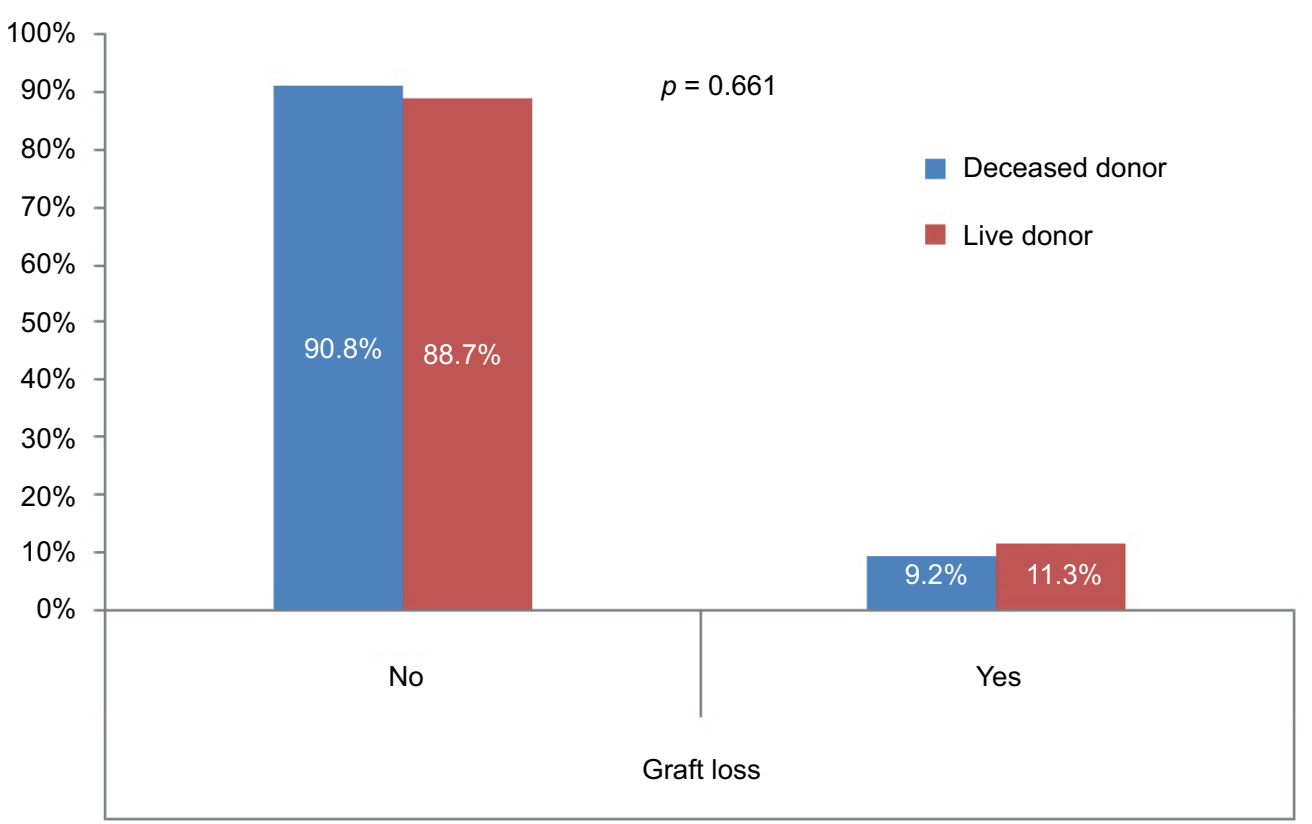

Figure 7 Graft survival rates in cadaveric and living donor recipients.

Table I Association between graft survival and demographic features

\begin{tabular}{lllll}
\hline Variant & & \multicolumn{2}{l}{ Graft rejection } & $\begin{array}{l}\text { Statistical } \\
\text { analysis, } \\
\text { p-value }\end{array}$ \\
\cline { 3 - 5 } & Yes & No & 0.050 \\
\hline Female & Donor & I0I (64.7\%) & I5 (88.2\%) & 0.555 \\
Gender & Recipient & $80(51.3 \%)$ & $10(58.8 \%)$ & 0.478 \\
Mean & Donor & 29.4 & 32.1 & 0.413 \\
Age & Recipient & 33.7 & 36.9 & \\
\hline
\end{tabular}

was $95 \%$ after 1 year and $86 \%$ at 5 years, and for living donor transplants $98 \%$ after 1 year and $93 \%$ at 5 years. ${ }^{1}$

The reviewed literature indicated that survival rates for living-donor graft was higher than that of cadaveric grafts, ${ }^{, 2,12,13}$ In contrast, our findings demonstrated a higher cadaveric graft survival rates $(90.8 \%)$ compared with living-donor grafts (88.7\%). This could be due to our younger donor population (mean age $=29.7 \pm 12.98$ years), which is probably the result of
Table 3 Characteristics of 4 patients with graft loss

\begin{tabular}{lllllll}
\hline Donor type & \multicolumn{2}{l}{ Donor } & & \multicolumn{2}{l}{ Recipient } & ESRD cause \\
\cline { 2 - 3 } \cline { 5 - 6 } \cline { 5 - 6 } & Age & Gender & & Age & Gender & \\
\hline Cadaveric & 29 & $\mathrm{~F}$ & & 44 & $\mathrm{M}$ & PKD \\
Cadaveric & 18 & $\mathrm{~F}$ & & 45 & $\mathrm{M}$ & HTN \\
Cadaveric & $\mathrm{I}$ & $\mathrm{F}$ & & 27 & $\mathrm{~F}$ & Unknown \\
Living & 32 & $\mathrm{~F}$ & & 48 & $\mathrm{M}$ & Unknown \\
\hline
\end{tabular}

Abbreviations: ESRD, end-stage renal disease; F, female; HTN, hypertension; $M$, male; PKD, polycystic kidney disease.

higher fatal road accidents in Iran. In other countries, the donor age is on the rise and it has been proven that grafts from older donors, result in a lower survival rate. ${ }^{14-16}$

Based on previously published studies, serum creatinine levels can be used as an indicator of graft rejection following renal transplantation. ${ }^{1,17}$ Overall 1-year graft survival in our cohort (90.2\%) was satisfactory and comparable with reports from large centers in developed countries. ${ }^{18-20}$ For instance, an

Table 2 Association between ESRD underlying causes and graft survival

\begin{tabular}{|c|c|c|c|c|c|c|c|}
\hline \multicolumn{2}{|c|}{$\begin{array}{l}\text { ESRD Causes } \\
\text { graft rejection }\end{array}$} & \multirow{2}{*}{$\begin{array}{l}\text { HTN } \\
22\end{array}$} & \multirow{2}{*}{$\begin{array}{l}\text { DM } \\
15\end{array}$} & \multirow{2}{*}{$\begin{array}{l}\begin{array}{l}\text { Chronic } \\
\text { pyelonephritis }\end{array} \\
12\end{array}$} & \multirow{2}{*}{$\begin{array}{l}\text { Others } \\
27 \\
\end{array}$} & \multirow{2}{*}{$\begin{array}{l}\text { Unknown } \\
80\end{array}$} & \multirow{2}{*}{$\begin{array}{l}\text { Tota } \\
156\end{array}$} \\
\hline No & $\mathrm{n}$ & & & & & & \\
\hline & $\%$ & 14.1 & 9.6 & 7.7 & 51.3 & 17.3 & 100 \\
\hline \multirow[t]{2}{*}{ Yes } & $\mathrm{n}$ & 2 & I & I & 4 & 9 & 17 \\
\hline & $\%$ & 11.8 & 5.9 & 5.9 & 23.5 & 52.9 & 100 \\
\hline \multirow[t]{2}{*}{ Total } & $\mathrm{n}$ & 24 & 16 & 13 & 31 & 89 & 173 \\
\hline & $\%$ & 13.9 & 9.2 & 7.5 & 17.9 & 51.4 & 100 \\
\hline
\end{tabular}

Note: Statistical analysis with Pearson Chi-Square (calculated by Monte Carlo method) $(p=0.960)$.

Abbreviations: DM, diabetes mellitis (pre-existing); ESRD, end-stage renal disease; HTN, hypertension. 
American study conducted by Cecka reported 1-year survival rates of $89 \%$ and $95 \%$ in 31,720 cadaveric grafts and 14,162 live-donor grafts, respectively. ${ }^{18}$

It was also suggested that the measurement of serum creatinine levels 1 year post-transplant could be a useful indicator of potential long-term allograft survival. ${ }^{1,2,17}$ This could be considered as a predictor of acceptable long-term survival rates in our center. However, to clarify such association, it is crucial to observe our patients over a longer period of time.

The graft survival rate is linked to numerous factors, including DGF, AREs, immunosuppressive regimen, and panel reactive antibodies. Similarly, a large number of donor- and recipient-related factors, including age, gender, graft source, and primary renal diagnosis can affect the outcomes. ${ }^{2,21-26}$ Due to retrospective nature of this study, we could not analyze all the aforementioned parameters. In our population, no statistically significant association between studied variants and graft survival rates were found, which could be due to low frequency of graft rejection in our center. However, we found that graft rejection was marginally, but not significantly, higher with female donors $(p=0.05)$. This finding was mentioned in other literature, in which they documented short- and long-term graft survival was lower with female donors irrespective of recipient's gender. ${ }^{27}$ In another large study, kidney graft function was significantly better at 1 and 10 years post-transplantation among organ recipients from male donors. ${ }^{28}$ There are various potential explanations for this fact and one of them would focus on body mass index (BMI) is an important factor that has a significant effect on gender-dependant responses to renal transplantation. This is understandable because a higher BMI results in a greater demand and formation of more nephrons in kidneys in order to compensate the higher demand, which subsequently leads to development of fewer nephrons in female's kidneys compared with males. As a result, female donors provide fewer nephrons compared with males. ${ }^{29}$

This was a retrospective study, and consequently it was necessary to make key assumptions about specific details of transplantation. These assumptions were made using appropriate clinical judgment in an attempt to best reflect the data present in the database and reflect clinical practice during the study. Future prospective studies are required to further investigate the nature of the relationship between the previously mentioned factors and long-term clinical outcomes; in addition, donor-recipient gender matching may be a factor to be considered in the future studies to improve graft outcome.
The following study had several limitations due to the conventional and inefficient patient records filing system that resulted in difficulty accessing important data and in several instances unavailability of the parameters required for this study.

\section{Conclusion}

Many of the technical problems surrounding renal transplantation have been overcome. The main problems that those patients who require transplants face nowadays are equity of access to transplantation and the availability of donor organs. Cadaveric organ transplantation is one of the preferred ways of treating patients with end-stage organ failure. In our study, we demonstrated that cadaveric graft survival is within acceptable international rates, although not statistically significantly higher than that of live-donor. Prompt diagnosis of brain death to provide optimal support to potential donors and trying to increase the donation rate must be the main focus of all transplant centers.

\section{Availability of data}

Data and materials supporting this article are available at Mashhad University of Medical Sciences Research Center and will be freely shared with any scientist wishing to use them for non-commercial purposes, without breaching confidentiality.

\section{Acknowledgment}

This research received no specific grant from any funding agency in the public, commercial, or not-for-profit sectors.

\section{Disclosure}

The authors report no conflicts of interest in this work.

\section{References}

1. McEwan P, Baboolal K, Dixon S, Conway P, Currie CJ. Patterns of graft and patient survival following renal transplantation and evaluation of serum creatinine as a predictor of survival: a review of data collected from one clinical centre over 34 years. Curr Med Res Opin. 2005;21(11):1793-1800.

2. Smith-Palmer J, Kalsekar A, Valentine W. Influence of renal function on long-term graft survival and patient survival in renal transplant recipients. Curr Med Res Opin. 2014;30(2):235-242.

3. Arefzadeh A, Lessanpezeshki M, Seifi S. The cost of hemodialysis in Iran. Saudi J Kidney Dis Transpl. 2009;20(2):307-311.

4. Kaitelidou D, Ziroyanis PN, Maniadakis N, Liaropoulos LL. Economic evaluation of hemodialysis: implications for technology assessment in Greece. Int J Technol Assess Health Care. 2005;21(1):40-46.

5. Hsu CY, Vittinghoff E, Lin F, Shlipak MG. The incidence of end-stage renal disease is increasing faster than the prevalence of chronic renal insufficiency. Ann Intern Med. 2004;141(2):95-101. 
6. Van Dijk PC, Jager KJ, Stengel B, Grönhagen-Riska C, Feest TG, Briggs JD. Renal replacement therapy for diabetic end-stage renal disease: data from 10 registries in Europe (1991-2000). Kidney Int. 2005;67(4): 1489-1499.

7. Najarian JS, Chavers BM, McHugh LE, Matas AJ. 20 years or more of follow-up of living kidney donors. Lancet. 1992;340(8823):807-810.

8. Ritz E, Rychlík I, Locatelli F, Halimi S. End-stage renal failure in type 2 diabetes: A medical catastrophe of worldwide dimensions. Am J Kidney Dis. 1999;34(5):795-808.

9. Hashiani AA, Rajaeefard A, Hasanzadeh J, et al. Ten-year graft survival of deceased-donor kidney transplantation: a single-center experience. Ren Fail. 2010;32(4):440-447.

10. Navva PK, Venkata Sreepada S, Shivanand Nayak K. Present status of renal replacement therapy in Asian Countries. Blood Purif. 2015;40(4): 280-287.

11. Ghafari A, Taghizade Afshari A, Makhdoomi Kh, et al. Cadaveric renal transplantation: a single-center experience. Transplant Proc. 2009;41(7):2775-2776.

12. Terasaki PI, Cecka JM, Gjertson DW, Takemoto S. High survival rates of kidney transplants from spousal and living unrelated donors. $N \mathrm{Engl}$ J Med. 1995;333(6):333-336.

13. Ramcharan T, Matas AJ. Long-term (20-37 years) follow-up of living kidney donors. Am J Transplant. 2002;2(10):959-964.

14. Hariharan S, McBride MA, Bennett LE, Cohen EP. Risk factors for renal allograft survival from older cadaver donors. Transplantation. 1997;64(12):1748-1754.

15. Alexander JW, Zola JC. Expanding the donor pool: use of marginal donors for solid organ transplantation. Clin Transplant. 1996;10(1 Pt 1): $1-19$.

16. Alexander JW, Bennett LE, Breen TJ. Effect of donor age on outcome of kidney transplantation. A two-year analysis of transplants reported to the United Network for Organ Sharing Registry. Transplantation. 1994;57(6):871-876.

17. Burgos D, Gonzalez-Molina M, Ruiz-Esteban P, et al. Rate of long-term graft loss has fallen among kidney transplants from cadaveric donors. Transplant Proc. 2012;44(9):2558-2560.
18. Cecka JM. The UNOS renal transplant registry. Clin Transpl. 2002: $1-20$.

19. Bresnahan BA, McBride MA, Cherikh WS, Hariharan S. Risk factors for renal allograft survival from pediatric cadaver donors: an analysis of united network for organ sharing data. Transplantation. 2001;72(2): 256-261.

20. Vasilescu ER, Ho EK, Colovai AI, et al. Alloantibodies and the outcome of cadaver kidney allografts. Hum Immunol. 2006;67(8):597-604.

21. Meier-Kriesche HU, Cibrik DM, Ojo AO, et al. Interaction between donor and recipient age in determining the risk of chronic renal allograft failure. J Am Geriatr Soc. 2002;50(1):14-17.

22. Womer KL, Vella JP, Sayegh MH. Chronic allograft dysfunction: mechanisms and new approaches to therapy. Semin Nephrol. 2000;20(2): 126-147.

23. Ojo AO, Hanson JA, Wolfe RA, Leichtman AB, Agodoa LY, Port FK. Long-term survival in renal transplant recipients with graft function. Kidney Int. 2000;57(1):307-313.

24. Takemoto SK, Terasaki PI, Gjertson DW, Cecka JM. Twelve years' experience with national sharing of HLA-matched cadaveric kidneys for transplantation. N Engl J Med. 2000;343(15):1078-1084.

25. Kwon OJ, Ha MK, Kwak JY, Lee HW. The impact of delayed graft function on graft survival in living donor kidney transplantation. Transplant Proc. 2003;35(1):92-93.

26. Meier-Kriesche HU, Kaplan B. Cyclosporine microemulsion and tacrolimus are associated with decreased chronic allograft failure and improved long-term graft survival as compared with sandimmune. $\mathrm{Am}$ J Transplant. 2002;2(1):100-104.

27. Jindal RM, Ryan JJ, Sajjad I, Murthy MH, Baines LS. Kidney transplantation and gender disparity. Am J Nephrol. 2005;25(5):474-483.

28. Cstet M. Gender issues in transplantation. Anesth Analg. 2008;107(1): 232-238.

29. Zhou JY, Cheng J, Huang HF, Shen Y, Jiang Y, Chen JH. The effect of donor-recipient gender mismatch on short and long-term graft survival in kidney transplantation: a systemic review and meta-analysis. Clin Transplant. 2013;27(5):764-771.
Transplant Research and Risk Management

\section{Publish your work in this journal}

Transplant Research and Risk Management is an international, peerreviewed open access journal focusing on all aspects of transplantation and risk management to achieve optimal outcomes in the recipient improving survival and quality of life. The manuscript management system is completely online and includes a very quick and fair peer-review system,

\section{Dovepress}

which is all easy to use. Visit http://www.dovepress.com/testimonials.php to read real quotes from published authors. 